\title{
Utility of Direct Immunofluorescence Studies in Subclassification of Autoimmune Sub-Epidermal Bullous Diseases: A 2-Year Study in a Tertiary Care Hospital
}

\author{
Supriya JAIN ${ }^{1}$, Vijaya BASAVARAJ ${ }^{2}$, Manjunath GUBBANNA VIMALA ${ }^{2}$ \\ Department of Pathology 'Bharati Vidyapeeth Deemed University Medical College and Hospital, SANGLI, INDIA and \\ 2JSS Medical College (JSS University), MYSORE, INDIA
}

\begin{abstract}
Objective: Sub-epidermal bullous disorders belong to immunobullous diseases which develop as a result of autoantibody action against epidermal basement membrane proteins. Clinically, they are tense bullae and do not rupture easily. They are classified into various forms based on histopathology and direct immunofluorescence patterns. This study was undertaken to assess the incidence of various sub-epidermal bullous disorders and the utility of direct immunofluorescence in accurately classifying them, and to study the intensity and pattern of immunofluorescence in various sub-epidermal bullous disorders

Material and Method: A 2-year study of 38 cases of sub-epidermal bullous disorders sent for direct immunofluorescence studies formed the study group. The specimens were processed as per standard protocols. The clinical details were obtained from case files and requisition sent for histopathological and direct immunofluorescence studies.

Results: Thirty-eight patients were diagnosed to have sub-epidermal bullous disorders over the period of 2 years. Twenty five cases of Bullous Pemphigoid, 5 cases of Dermatitis Herpetiformis, 3 cases of Linear IgA Bullous disorder, 2 cases of Bullous Systemic Lupus Erythematoses and 1 case each of Epidermolysis Bullosa Acquisita, Cicatricial Pemphigoid and Pemphigus Gestationis was diagnosed. Positive direct immunofluorescence was seen in $91.3 \%$ of the cases.

Conclusion: Histopathology alone cannot classify sub-epidermal bullous disorders and direct immunofluorescence studies are mandatory in all of them. Bullous Pemphigoid needs to be distinguished from Epidermolysis Bullosa Acquisita which requires Salt split direct immunofluorescence studies. Dermatitis Herpetiformis, Bullous Systemic Lupus Erythematosus and Linear IgA Bullous disorder show more or less similar histological picture with neutrophilic microabscess. Direct immunofluorescence studies help in the majority of cases but further testing such as immunoblotting, immunoelectron microscopy or indirect immunofluorescence becomes essential in cases with overlapping features.
\end{abstract}

Key Words: Direct immunofluorescence, Bullous skin diseases, Bullous Pemphigoid, Dermatitis Herpetiformis

\section{INTRODUCTION}

Sub-epidermal bullous disorders (SEBDs) are characterized by autoantibodies specifically against the components of the epidermal basement membrane zone (1). SEBDs embrace the following entities: Bullous Pemphigoid (BP), Cicatricial Pemphigoid (CP), Epidermolysis Bullosa Acquisita (EBA), Dermatitis Herpetiformis (DH), Linear IgA Bullous Dermatoses (LABD) and Bullous Systemic Lupus Erythematosus (SLE).

SEBDs are characterized clinically by the presence of cutaneous and/or mucosal blisters on a hemorrhagic or non-hemorrhagic base, associated with intense pruritus. Histology shows all SEBD's characterized by sub-epidermal split with inflammatory infiltrate in the bullous cavity. Direct immunofluorescence (DIF) studies show deposition

(Turk Patoloji Derg 2016, 32:91-98)

Received : 06.09.2015 Accepted : 30.11.2015 of immunoglobulins and/or complement at the basement membrane zone, with the exception of $\mathrm{DH}$, where the deposits are seen in the dermal papillae.

\section{MATERIALS and METHODS}

The study was conducted during a 2-year period. Two 5 $\mathrm{mm}$ punch skin biopsies, one in $10 \%$ formalin and the other in normal saline, were sent from patients with a suspected clinical diagnosis of vesiculobullous disease to the department of pathology for both histopathology and DIF studies, respectively. Biopsy specimens sent in formalin were processed and serial haematoxylin and eosin sections were analyzed. The biopsy for DIF studies was sent in normal saline and was processed as follows. Specimens were embedded in a cryomatrix embedding medium and snap-frozen at $-40^{\circ} \mathrm{C}$ until sectioned. Cryostat tissue

Correspondence: Supriya JAIN

Department of Pathology, Bharati Vidyapeeth Deemed University Medical

College and Hospital, SANGLI, INDIA

E-mail: sups.ain@gmail.com Phone: +919986999968 
sections of 4 microns were air-dried and washed thrice with phosphate-buffered saline (PBS), pH 7.4, for 10 minutes before being overlaid for 30 minutes with fluorescein isothiocyanate-conjugated rabbit anti-human IgG, IgA, IgM and C3. Sections were then incubated in a humidified chamber at room temperature, washed thrice with PBS at $\mathrm{pH} 7.4$ for 10 minutes and mounted with glycerine before viewing with a fluorescent microscope (Olympus BX-40).

A total of 75 cases of immunobullous diseases were evaluated of which 38 cases were from the SEBD group and were included in the study. The remaining 44 cases belonged to the pemphigus group and were excluded from the study. Clinical data provided along with the biopsy specimen were documented separately. DIF patterns were interpreted according to standard criteria.

\section{RESULTS}

Thirty-eight patients were diagnosed as SEBD over the period of 2 years. Twenty five cases were of BP (65.7\%), 5 cases were of DH (13.1\%), 3 cases were of LABD (7.8\%), 2 cases were of Bullous SLE (5.2\%), and there was 1 case each of EBA, CP and Pemphigus Gestationis (PG) (2.6\%).

$\mathrm{BP}$ was the most common lesion among SEBDs followed by $\mathrm{DH}, \mathrm{LABD}$ and Bullous SLE. The clinical features and histopathological findings are shown in Table I. Histopathologically all the cases of BP except for three cases showed a sub-epidermal bulla with fibrin and inflammatory infiltrate in the bullous cavity. Three cases showed an intraepidermal bulla with regenerative epithelium on the floor. Eosinophils were the most common inflammatory infiltrate seen followed by neutrophils.

Table I: The clinical and histopathological findings of sub-epidermal bullous diseases

\begin{tabular}{|c|c|c|c|c|c|c|}
\hline \multirow[b]{2}{*}{ Disease entity } & \multirow[b]{2}{*}{$\begin{array}{l}\text { Mean } \\
\text { age }\end{array}$} & \multirow[b]{2}{*}{ Clinical findings } & \multirow[b]{2}{*}{ Site predilection } & \multicolumn{3}{|c|}{ Histopathology } \\
\hline & & & & Level of split & $\begin{array}{l}\text { Adjacent } \\
\text { epidermis }\end{array}$ & $\begin{array}{l}\text { Contents of } \\
\text { bulla }\end{array}$ \\
\hline Bullous pemphigoid & 60 & $\begin{array}{l}\text { Multiple fluid } \\
\text { filled vesicles } \\
\text { which rupture } \\
\text { with crusting and } \\
\text { erosions }\end{array}$ & $\begin{array}{l}\text { Lower limbs }>\text { upper } \\
\text { limbs }>\text { whole body }\end{array}$ & Sub-epidermal & $\begin{array}{l}\text { Eosinophilic } \\
\text { spongiosis }\end{array}$ & Eosinophils \\
\hline $\begin{array}{l}\text { Dermatitis } \\
\text { herpetiformis }\end{array}$ & 37 & $\begin{array}{l}\text { Multiple papulo- } \\
\text { pruritic lesions } \\
\text { with severe itching }\end{array}$ & $\begin{array}{l}\text { Chest }>\text { scapular } \\
\text { region }>\text { back }\end{array}$ & Sub-epidermal & $\begin{array}{l}\text { Neutrophilic } \\
\text { collections } \\
\text { in papillary } \\
\text { dermis }\end{array}$ & $\begin{array}{l}\text { Neutrophils, } \\
\text { eosinophils, } \\
\text { lymphocytes } \\
\text { and } \\
\text { karyorrhexis. }\end{array}$ \\
\hline Bullous SLE & 28 & $\begin{array}{l}\text { Multiple fluid } \\
\text { filled lesions with } \\
\text { urticarial plaques }\end{array}$ & Chest, upper back & Sub-epidermal & & $\begin{array}{l}\text { Neutrophilic } \\
\text { collections } \\
\text { in papillary } \\
\text { dermis and } \\
\text { karyorrhexis. }\end{array}$ \\
\hline Linear IgA disease & 11 & $\begin{array}{l}\text { Fluid filled lesions, } \\
\text { tense vesicles } \\
\text { to hemorrhagic } \\
\text { bullae. }\end{array}$ & All over the body & Sub-epidermal & $\begin{array}{l}\text { Neutrophils, } \\
\text { eosinophils } \\
\text { and fibrin. }\end{array}$ & $\begin{array}{l}\text { Neutrophilic } \\
\text { collections } \\
\text { in papillary } \\
\text { dermis. }\end{array}$ \\
\hline Pemphigoid gestationis & 24 & $\begin{array}{l}\text { Multiple urticarial } \\
\text { plaques and } \\
\text { papules }\end{array}$ & $\begin{array}{l}\text { Abdomen, back and } \\
\text { forearm. }\end{array}$ & Sub-epidermal & & \\
\hline $\begin{array}{l}\text { Epidermolysis bullosa } \\
\text { acquisita }\end{array}$ & 67 & $\begin{array}{l}\text { Multiple tense } \\
\text { bullae }\end{array}$ & Chest, oral cavity & Sub-epidermal & $\begin{array}{l}\text { Eosinophils, } \\
\text { lymphocytes } \\
\text { and fibrin } \\
\end{array}$ & \\
\hline Cicatricial pemphigoid & & & Oral cavity & & Fibrosis & \\
\hline
\end{tabular}



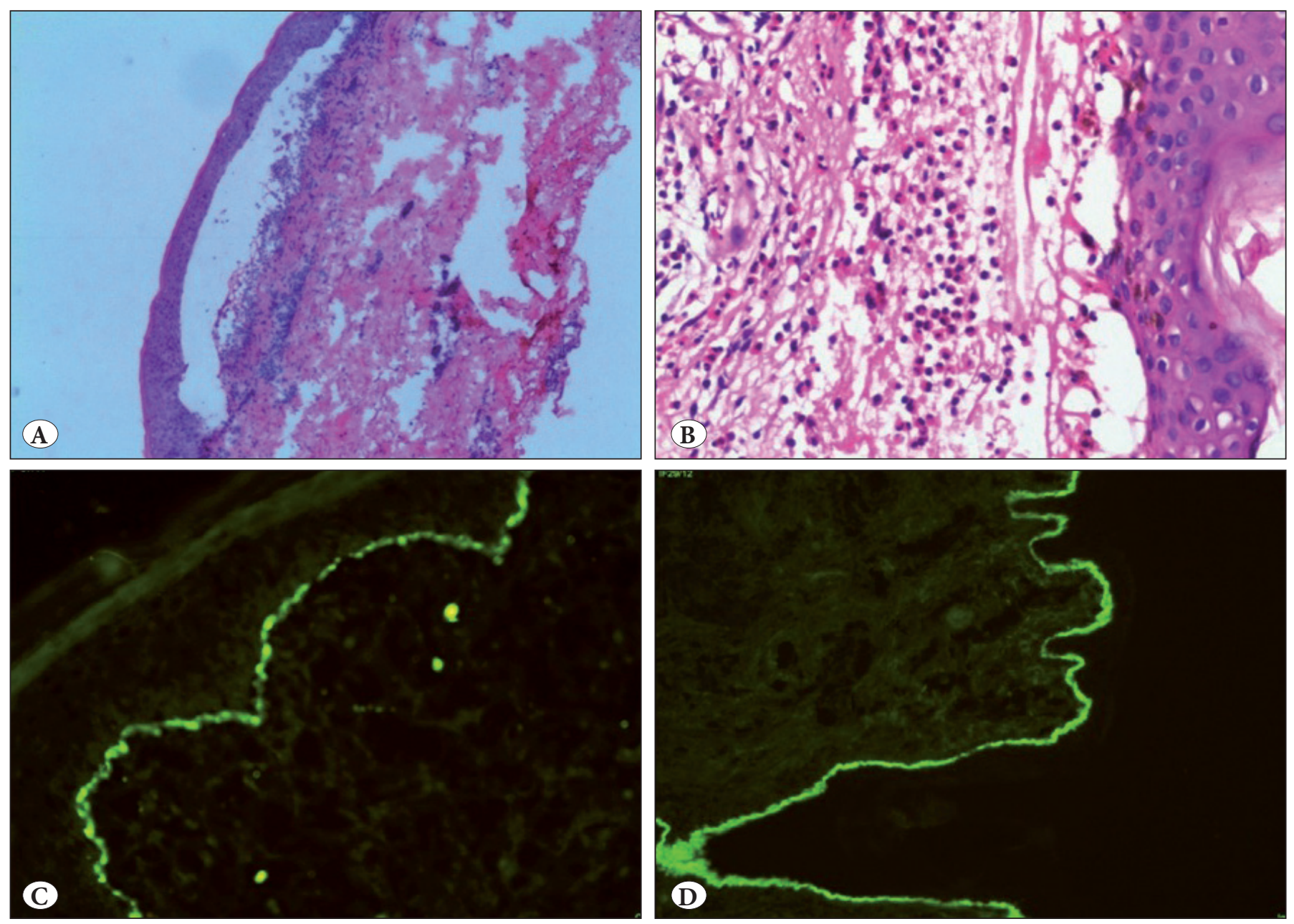

Figure 1: Bullous pemphigoid: A) Scanner view showing sub-epidermal bulla with inflammatory infiltrate in bullous cavity (H\&E; 440 ), B) Low power view showing sub-epidermal bulla with eosinophils and exudates in bullous cavity (H\&E; x100), C,D) Linear deposition of C3 and IgG along the dermo-epidermal junction (IF; x200).

The adjacent epidermis showed eosinophilic spongiosis in 8 cases. (Table I, Figure 1A-B). DIF studies showed linear deposition of $\mathrm{C} 3$ along the dermo-epidermal junction in all the cases (100\%) and deposition of IgG in $91.8 \%$ of the cases (Figure 1C-D). The fluorescence was appreciable at lower magnification of the $10 \mathrm{x}$ objective in $66.6 \%$ of cases and at $40 \mathrm{x}$ in the remaining $33.3 \%$ of the cases representing a lower intensity of fluorescence.

PG showed identical histopathological features as BP with only C3 deposition along the dermoepidermal junction. CP on DIF studies showed deposition of IgG and IgM along the dermo-epidermal junction. The histopathology showed fibrosis of the subepithelial region.

DH showed sub-epidermal clefting with presence of fibrin and neutrophils. There was denudation of the epidermis with collection of neutrophils and fibrin in the underlying papillary dermis. DIF studies showed deposition of IgA in granular and fibrillary pattern in the dermal papillae.

LABD showed sub-epidermal bulla rich in neutrophils and eosinophils (Figure 2A). DIF studies showed a linear homogenous deposition of IgA along the basement membrane zone. One case showed deposition of IgM along with IgA (Figure 2B,C).

Bullous SLE showed epidermis displaying focal basal cell vacuolar degeneration and a small sub-epidermal cleft was seen with intense collection of neutrophils in the papillary and mid dermis with karyorrhexis (Figure 3A). DIF studies showed granular and linear deposits of IgG, IgA, IgM and C3 along the dermoepidermal junction and around hair follicle epithelium (Figure 3B-D).

EBA showed deposition of $\operatorname{IgG}$ and $\mathrm{C} 3$ along DEJ in continous and linear pattern (Figure 4) 

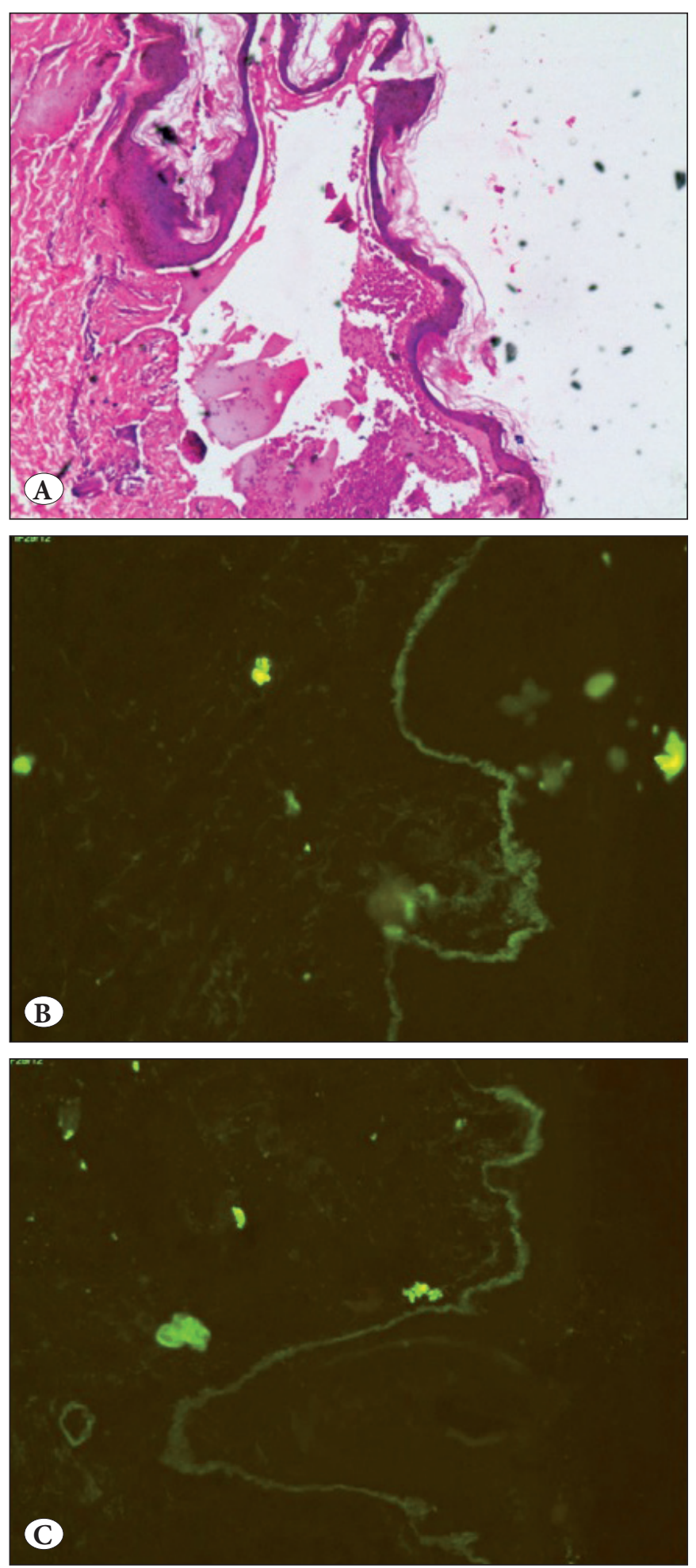

Figure 2: A) Linear IgA bullous dermatosis showing subepidermal bulla rich in neutrophils, B,C) Immunofluorescence showing linear homogenous deposition of $\operatorname{IgA}$ and IgM along the basement membrane zone (IF; x200).

\section{DISCUSSION}

Bullous Pemphigoid usually occurs in elderly individuals and presents with multiple tense bullae commonly on the extremities and the trunk. Erosions in the oral cavity are not infrequent $(2,3)$. BP has been reported in association with diabetes, ulcerative colitis and vitiligo (2). Association with diabetes was seen in $26 \%$ and with hypertension in $13 \%$ of our patients.

Histopathology of BP may show a regenerative epithelium at the floor of the bulla making it difficult to discern the anatomical level of split and give a false negative impression of intraepidermal bulla. Such cases warrant DIF studies. A biopsy from an older lesion causes such changes and difficulty in interpretation of the biopsy and therefore a biopsy from an early bulla is advised for histopathological study.

DIF studies in BP show linear deposition of $\mathrm{C} 3$ along the dermo-epidermal junction in all the cases $(100 \%)$ whereas deposition of IgG was seen in $91.8 \%$ cases. Hence, C3 has a higher sensitivity and specificity as compared to IgG. This was in accordance to the other studies reported in the literature $(2,3)$.

PG is common in the second to third trimester of pregnancy and presents with itchy plaques, papules and vesicles initially on the abdomen and later involving the extremities. Cases reported advocate the average age for the appearance of lesions as around 21 week of gestation ( $2^{\text {nd }}$ or $3^{\text {rd }}$ trimester $)$ with the lesions typically beginning on the abdomen around umbilicus as was noted in our case (4). The etiology is controversial but it is attributed to autoimmune reaction against placental tissue (5). A few studies have shown an associated underlying hydatidiform mole or choriocarcinoma. Hence it is essential to thoroughly evaluate for an underlying cause (5). There was no such underlying lesion in our case. The patient had a history of similar lesions of mild severity in the previous pregnancy, which resolved after delivery, as conventional for PG. It usually recurs in subsequent pregnancies, when it tends to be more severe.

PG on DIF shows linear deposits of C3 along the dermoepidermal junction. Similar findings have been observed by other authors $(2,3,6)$. DIF studies are also required to differentiate pemphigoid gestationis from other cutaneous lesions occurring in pregnancy, especially pruritic urticarial papules and plaques of pregnancy, the latter showing negative results on DIF (6).

$\mathrm{DH}$ comprised the second most common lesion among cases of SEBD. Patients present with intense itchy papulo- 

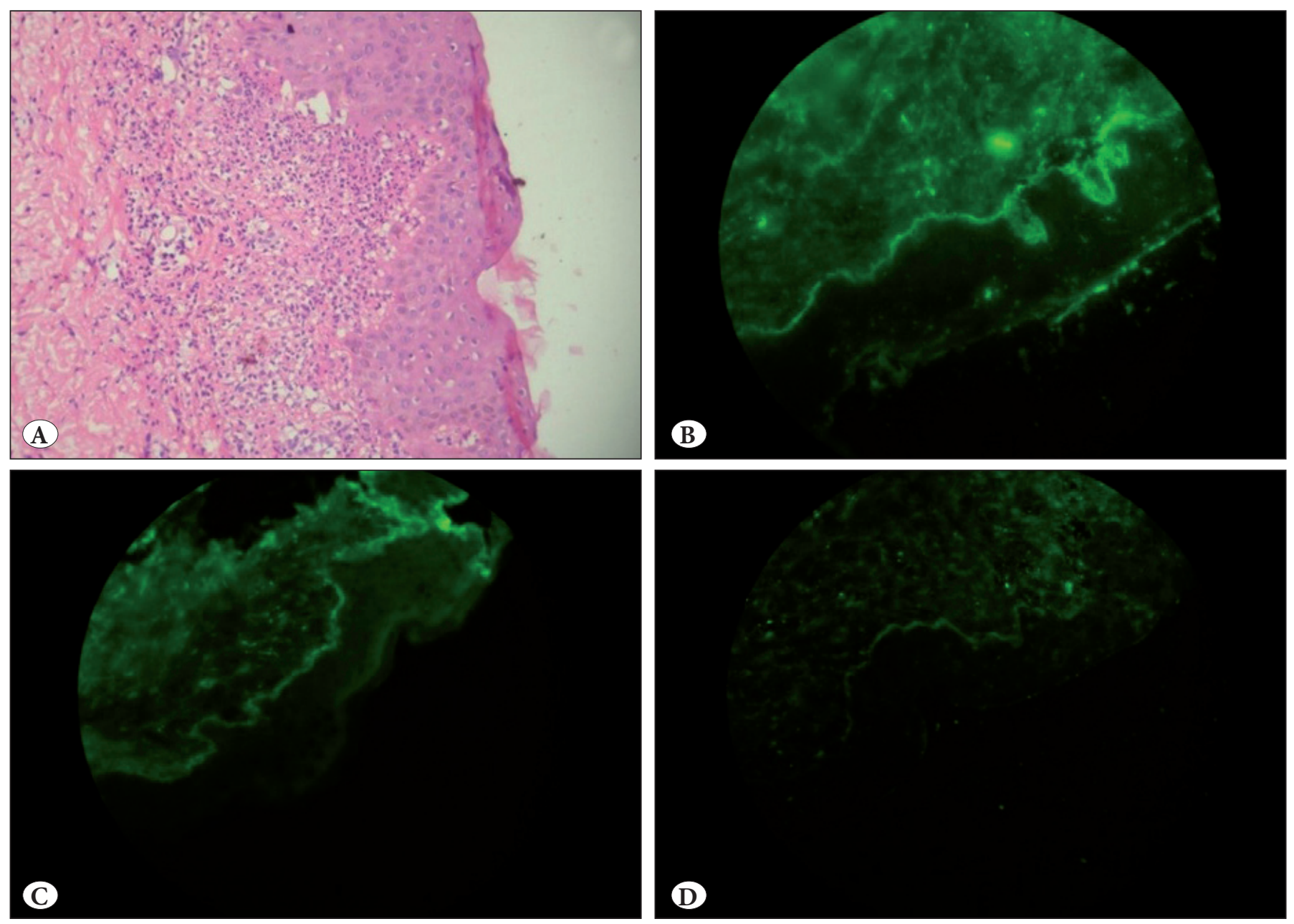

Figure 3: A) Bullous systemic lupus erythematosus showing epidermis with focal basal cell vacuolar degeneration, small subepidermal cleft with intense collection of neutrophils, in the papillary and mid dermis with karyorrhexis, B-D) Immunofluorescence showing granular and linear deposits of IgG, IgA and IgM along the dermo-epidermal junction respectively (IF; x200).

pruritic lesions on the extremities, abdomen and chest. Intact bullae are rarely seen in DH because the lesions are scratched due to intense pruritus and thus the vesicles are replaced by excoriations. According to the literature, mucous membrane involvement is seen infrequently (7-9). There was no mucous membrane involvement in any of our cases. DH is known to be associated with celiac disease and other auto-immune diseases. In our study, none of the cases had a history of diarrhoea or any significant medical history. We found a good number of patients with intact bullae (66.6\%). This finding, along with a lower prevalence of intestinal symptoms, might reflect a different phenotype which is more common in our population. A similar pattern has also been noted in a study by Fuertes et al. in Spain (10).

Histopathology usually showed a sub-epidermal clefting with neutrophilic microabscess, In three of the cases, there was no discernible sub-epidermal bulla due to denudation of the epidermis with collection of neutrophils and fibrin in the underlying papillary dermis. The presence of neutrophilic microabscess in the papillary dermis authenticates the diagnosis (Table II). Although DH was included in the clinical differential diagnosis of many cases of SEBD, it was proved histopathologically only in 5 cases and DIF was positive only in two cases. This result accounted the lowest compliance (66\%) in our study. As has been stated by Lebe et al., one of the reasons for discordance could be the tendency of the clinicians to include DH as differential diagnosis in all pruritic skin lesions (11). DIF studies show deposition of IgA in a granular and fibrillary pattern in the dermal papillae. There were a high number of false negatives and the reasons could be biopsy from the involved skin, biopsy from an area that has never been involved, the patient being on a long-term gluten free diet, and pruritic papulo-vesicular eruptions of DH that evolved 
Table II: Direct immunofluorescence findings in sub-epidermal bullous diseases

\begin{tabular}{|c|c|c|c|}
\hline Disease entity & No. of cases & DIF findings & Level of split / histopathology \\
\hline Bullous pemphigoid & 25 & \multirow{3}{*}{$\begin{array}{l}\text { Deposition of Immunoglobulins along BMZ in } \\
\text { linear pattern. } \\
\text { C3> C3 + IgG }\end{array}$} & Sub-epidermal bulla \\
\hline Cicatricial pemphigoid & 1 & & Fibrosis in mucosa \\
\hline Herpes gestationis & 1 & & Sub-epidermal bulla \\
\hline $\begin{array}{l}\text { Dermatitis } \\
\text { herpetiformis }\end{array}$ & $2 / 5^{\#}$ & $\begin{array}{l}\text { IgA deposition in papillary dermis in fibrillar } \\
\text { pattern }\end{array}$ & $\begin{array}{l}\text { Sub-epidermal bulla, } \\
\text { Neutrophilic infiltrate in } \\
\text { papillary dermis }\end{array}$ \\
\hline $\begin{array}{l}\text { Linear IgA bullous } \\
\text { dermatoses }\end{array}$ & 3 & $\begin{array}{l}\text { Deposition of IgA along BMZ in a linear } \\
\text { homogenous fashion. }\end{array}$ & Sub-epidermal bulla \\
\hline Bullous SLE & $2^{*}$ & $\begin{array}{l}\text { Deposition of IgG, IgA, IgM and C3 in } \\
\text { continuous/discontinuous granular pattern } \\
\text { along DEJ }\end{array}$ & Sub-epidermal clefting \\
\hline $\begin{array}{l}\text { Epidermolysis bullosa } \\
\text { Acquisita }\end{array}$ & 1 & $\begin{array}{l}\text { Deposition of IgG and C3 along DEJ in } \\
\text { continuous and linear pattern } \\
\text { Salt-split-floor of bulla }\end{array}$ & Sub-epidermal bulla \\
\hline
\end{tabular}

DIF: Direct immunofluorescence, BMZ: Basal membrane zone, DEJ: Dermoepidermal junction.

${ }^{*} 2^{\text {nd }}$ case of Bullous SLE was not confirmed on serology, \# 3 cases were DIF negative

and disappeared rapidly $(9,11)$. In one of the largest series, reported by Alonso et al. in 2007, granular deposits of IgA at the dermal papillae was considered the hallmark of $\mathrm{DH}$, and this was reproduced in a study of the author who found a sensitivity of $92.4 \%$ (9). However, subsequent studies and the present study have failed to reproduce the same (12-15). In our study and few other studies, it was found that $\mathrm{DH}$ had least concordance when clinical diagnosis and histopathological diagnosis was considered with DIF studies $(11,15)$. All these findings in the more recent studies prod us to think whether deposition of IgA in the dermal

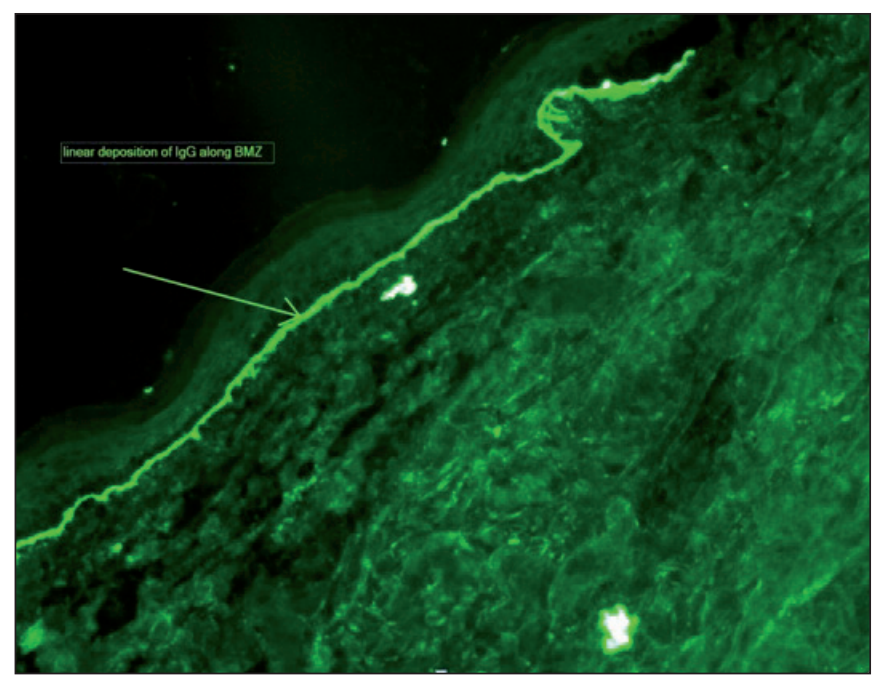

Figure 4: Epidermolysis bullosa acquisita showing deposition of IgG along the floor of the bulla (IF; x200). papillae should be considered as a diagnostic hallmark in $\mathrm{DH}(14,15)$ or should the consideration be given to a combination of clinical, histologic and immunologic and more specific presence of IgA anti-endomysial antibodies?

LABD was third in frequency among SEBDs. Two were childhood type and one was adult type $(16,17)$. The patient present with vesicles of varying sizes, tense to flaccid and hemorrhagic bullae. Hemorrhagic bullae have also been reported by Rogers et al. (18). Patients with childhood type of LABD present with tense bullae and vesicles with erosions and central crusting. Histopathology shows sub-epidermal bulla (Table II). Eosinophils and neutrophils can be seen in the bulla cavity and around blood vessels in the upper dermis. The presence of eosinophils poses a diagnostic dilemma between LABD and bullous pemphigoid (16). The clinical findings and DIF findings help in resolving the diagnostic issue. DIF studies show deposition of IgA along the dermoepidermal junction in a linear and homogenous pattern. Deposition of IgG and IgM along the DEJ in addition to deposition of IgA in linear fashion may also be present as was seen in our case.

Chan et al. suggested that LABD and BP can usually be differentiated based on the greater fluorescence intensity of one of the antibodies, either IgA or IgG, in combination with clinical and immunological features (19). This diagnostic dilemma further surges when there is additional deposition of C3 along the DEJ along with IgA/IgG. Powell et al. observed that irrespective of whether $\operatorname{IgA}$ or $\operatorname{IgG}$ is 
predominantly deposited, the clinical features, response to treatment with dapsone, and prognosis of the childhood disease remain the same (20). Therefore, the classical cases with predominant IgA deposition (linear IgA disease) as well as mixed immune bullous disease (linear IgG / IgA disease or linear IgA / IgG disease) seem to be practically the same entity. The division of this clinically homogeneous entity into the classical form and variants, based on the immunopathology seems artificial, futile, and confusing. Considering all these factors, indiscriminate use of terms like linear IgA disease, linear IgA bullous dermatoses of childhood, mixed immune bullous disease, linear IgG / IgA disease and so on, should best be avoided in childhood cases (21). Haneef et al. proposed that all cases showing the typical clinical picture of 'cluster of jewels' or 'string of pearls' sign should be included under the broad term 'chronic bullous disease of childhood,' irrespective of the nature of the immune deposits, as the clinical behavior is same and the patient responds well to the treatment (21).

Bullous SLE is a rare cutaneous manifestation of systemic lupus erythematosus (SLE). In $23 \%$ of patients with SLE, cutaneous involvement is the initial manifestation. Patients present with cutaneous blisters along with other signs and symptoms of SLE. In a few cases including ours, cutaneous bullae were initial manifestations of SLE, and SLE presenting as a bullous eruption is indeed a rare manifestation (22). Histopathology shows sub-epidermal clefting and DIF studies shows "full house" deposition of immunoglobulins and C3 in granular and linear pattern at the dermoepidermal junction and sometimes around adnexal epithelium. DIF is essential in making the diagnosis of bullous SLE.

EBA is another SEBD that merits mention as it is not infrequent. Although a clinical history of mechanobullous eruption aids in making the diagnosis, histopathology and immunofluorescence similarity warrants a salt split immunofluorescence study which shows deposition of immunoreactants, C3 and IgG along the floor of the split in EBA.

EBA and bullous SLE are sub-epidermal blisters that target type VII collagen, but can look identical to BP on DIF. Saltsplit DIF studies will distinguish between these entities. The patterns of immunoreactant deposition in bullous SLE can be granular, linear and rarely fibrillar (23). The dermal floor pattern of indirect immunofluorescence on salt-split skin substrate is found in the sera of patients with both bullous SLE and EBA (24). Immunoelectron microscopy and serological tests for bullous SLE become the gold standard in distinguishing the two disorders in such cases.
The clinical manifestations also help to distinguish between Bullous SLE and EBA.

In conclusion, SEBDs present with tense bullae clinically with an anatomical level of split in the sub-epidermal location. Eosinophil rich infiltrates are characteristic of bullous pemphigoid whereas neutrophilic rich infiltrates are seen in DH and LABD. EBA usually shows a cell-poor sub-epidermal bulla. BP of the cell-poor type and EBA may be difficult to distinguish both histologically and on DIF. A salt split skin IF helps in differentiating cell-poor BP from an EBA. The nonavailability of salt split skin immunofluorescence studies was the limitation of the study. In a few cases with overlapping features, further testing such as immunoblotting, immunoelectron microscope or indirect immunofluorescence becomes essential.

\section{REFERENCES}

1. Bilic M, Mutasim D. Bullous pemphigoid. In: Enna SJ, David BB, editors. xPharm: The Comprehensive Pharmacology Reference. New York, NY: Elsevier Science Inc; 2007.1-9.

2. Esmaili N, Hallaji Z, Soori T, Chams Davatchi C. Bullous Pemphigoid in Iranian patients: A descriptive study on 122 cases. Acta Medica Iranica. 2012;50:335-8.

3. Kulthanan K, Chularojanamontri L, Tuchinda P, Sirikudta W, Pinkaew S. Prevalence and clinical features of Thai patients with bullous pemphigoid. Asian Pac J Allergy Immunol. 2011;29:6672.

4. Kroumpouzos G. Specific dermatoses of pregnancy: Advances and controversies. Expert Review Dermatology. 2010;5:633-48.

5. Lu PD, Ralston J, Kamino H, Stein JA. Pemphigoid gestationis. Dermatol Online J. 2010;16:10.

6. Aronson IK, Bond S, Fiedler VC, Vomvouras S, Gruber D, Ruiz C. Pruritic urticarial papules and plaques of pregnancy: Clinical and immunopathologic observations in 57 patients. J Am Acad Dermatol. 1998;39:933-9.

7. Kabir AN, Das RK, Kamal M. Direct immunofluorescence test of skin biopsy samples -result of 204 cases. Dinajpur Med Col J. 2009;2:8-12.

8. Mutasim DF, Adams BB. Immunofluorescence in dermatology. J Am Acad Dermatol. 2001;45:803-22.

9. Alonso-Llamazares J, Gibson LE, Rogers RS 3rd. Clinical, pathologic, and immunopathologic features of dermatitis herpetiformis: Review of the Mayo Clinic experience. Int J Dermatol. 2007;46:910-9.

10. Fuertes I, Mascaro JM, Bombi JA, Iranzo P. A retrospective study of clinical, histological and immunological characteristics in patients with dermatitis herpetiformis. The experience of Hospital Clinic De Barcelona, Spain between 1995 and 2010 and a review of literature. Actas Dermosifiliogr. 2011;102:699-705.

11. Lebe B, Nifioglu GG, Seyrek S, Ellidokuz H. Evaluation of clinical and histopathologic/direct immunofluorescence diagnosis in autoimmune vesiculobullous dermatitis: Utility of direct immunofluorescence. Turk Patoloji Derg. 2012;28:11-6. 
12. Shih PY, Kuo TT, Chiou CC, Wang JR, YU KJ, HO HC. Transition from pemphigus vulgaris to pemphigus foliaceus. Dermatol Sinica. 2009;27:52-8.

13. Feliciani C, Motta A, Castellaneta M, Federica M, De Benedetto A, Toto P, Tulli A. Coexisting pemphigus vulgaris and pemphigus foliaceus in the same patient. Int J Dermatol. 2005;44:139-41.

14. Sousa L, Bajanca R, Cabral J, Fiadeiro T. Dermatitis herpetiformis: Should direct immunofluorescence be the only diagnostic criterion? Pediatr Dermatol. 2002;19:336-9.

15. Inchara YK, Rajalakshmi T. Direct immunofluorescence in cutaneous vesiculobullous lesions. Indian J Pathol Microbiol. 2007;50:730-2.

16. Tsai IC, Chu CY, Chen HJ, Wang LF, Chiu HC. Linear IgA bullous dermatosis: A clinical study of 16 cases at National Taiwan University Hospital. Dermatol Sinica. 2010;28:21-6.

17. Wojnarowska F, Marsden RA, Bhogal B, Black MM. Chronic bullous disease of childhood, cicatricial pemphigoid, and linear IgA disease of adults: A comparative study demonstrating clinical and immunological overlap. J Am Acad Dermatol. 1988;19:792805.

18. Rogers M, Barlett B, Walder B, Cains G. Chronic bullous disease of childhood- aspects of management. Australas J Dermatol. 1982;23:62-9.
19. Chan LS, Traczyk T, Taylor TB, Eramo LR, Woodley DT, Zone JJ. Linear IgA bullous dermatosis. Characterisation of a subset of patients with concurrent IgA and IgG anti-basement membrane autoantibodies. Arch Dermatol. 1995;131:1432-7.

20. Powell J, Kirtschig G, Allen J, Dean D, Wojnarowska F. Mixed immunobullous disease of childhood: A good response to antimicrobials. Br J Dermatol. 2001;144:769-74.

21. Haneef NS, Ramachandra S, Metta AK, Srujana L. Chronic bullous disease of childhood with IgG predominance: What is the locus standi? Indian J Dermatol. 2012;57:285-7.

22. Pedro SD, Dahl MV. Direct immunofluorescence of bullous systemic lupus erythematosus. Arch Dermatol. 1973;107:118-20.

23. Gammon WR, Briggaman RA. Bullous SLE: A phenotypically distinctive but immunologically heterogeneous bullous disorder. J Invest Dermatol. 1993;100:28-34.

24. Chan LS, Lapiere JC, Chen M, Traczyk T, Mancini AJ, Paller AS, Woodley DT, Marinkovich MP. Bullous systemic lupus erythematosus with autoantibodies recognizing multiple skin basement membrane components, bullous pemphigoid antigen 1, laminin-5, laminin-6, and type VII collagen. Arch Dermatol. 1999;135:569-73. 